\title{
Viscoplastic flow of functional cellular materials with use of peridynamics
}

\author{
Eligiusz Postek $\cdot$ Zdzisław Nowak (D) - Ryszard B. Pęcherski
}

Received: 9 November 2020/ Accepted: 3 June 2021 / Published online: 26 June 2021

(C) The Author(s) 2021

\begin{abstract}
The subject of the study is the deformation of the oxygen-free high conductivity copper. The copper sample is given in the form of a foam. The sample undergoes an impact into an elastic wall. The strain rate hardening effect is investigated. The numerical model of the open-cell foam skeleton is prepared in the framework of the peridynamics method. The dynamic process of compression with different impact velocities is simulated. It has been found that the strain rate hardening effect is essential for the load-carrying capacity of the material under study. Taylor impact test of solid cylinder analysis precedes the analysis of the metallic foam.
\end{abstract}

Keywords Cellular materials · OFHC copper . Elastic-viscoplastic model $\cdot$ Strain rate hardening . Peridynamics $\cdot$ Foam skeleton

E. Postek $(\bowtie)$

Department of Information and Computational Science, Institute of Fundamental Technological Research, Polish Academy of Sciences, Warsaw, Poland

e-mail: epostek@ippt.pan.pl

Z. Nowak · R. B. Pęcherski

Department of Theory of Continuous Media and Nanostructures, Institute of Fundamental Technological Research, Polish Academy of Sciences, Warsaw, Poland e-mail: znowak@ippt.pan.pl

R. B. Pęcherski

e-mail: rpecher@ippt.pan.pl

\section{Introduction}

Nonlocality or a characteristic length scale in modelling of multiphase materials in the continuum theory approach can be associated with the physical interactions of material points within finite distance. The effects of these nonlocal constituents are usually not incorporated in conventional constitutive models for multiphase materials in classical solid mechanics. In the local theory, it is assumed that material points only interact with their immediate neighbours. This limitation of the local continuum theory for modelling multiphase materials is not considered in a nonlocal mechanical model. To overcome the above-mentioned limitations, state-based peridynamics can be applied. The direct precursors of the peridynamics are the nonlocal descriptions of crystal mechanics, see Kunin [1] and Rogula [2]. The state-based peridynamics is a continuum theory that employs a non-local model to describe material properties. The essence of peridynamics is that spatial integration, rather than spatial differentiation, is used to compute the force state on a material point (Silling et al. [3]). In the state-based peridynamics, the momentum balance equation is represented by an integral formulation instead of the partial differential equations. A peridynamic material model corresponds to a classical material model when the strain energy density of both the classical and the peridynamic material are equal under affine deformations. The constitutive laws can be formulated based 
on a non-local version of classical non-linear strain measures directly computed from an approximate non-local deformation gradient (Silling et al. [3]). The form of such laws provides a description of deformation near a local point based on a weighted average of the deformation of all the neighbouring bonds. The resulting force vector-state for constitutive correspondence is in the form of the force vector-state and leads to a peridynamic formulation that conserves angular momentum provided that the classical constitutive model used to ensure conservation of angular momentum and is non polar. It happens if the resulting Cauchy stress is symmetric (Silling et al. [3]).

In literature, coupled formulations involving peridynamics have been developed to analyse thermal, chemical, diffusion, and electrical problems as well as for porous flow [4-13]. As the peridynamics formulation can inherently account for discontinuities in the displacement field, peridynamics has been predominantly used to solve fracture and damage problems $[14,15]$. The extent of peridynamics is not restricted to fracture mechanics. The concise categorization of the peridynamics applications and related contributions in the literature, in particular, are presented in the review paper by Javili et al. [16]. There are described applications of gradient plasticity methods, fractional methods, micropolar plasticity methods, combinations of molecular dynamics and finite element method with peridynamics. An alternative coupling of peridynamics and finite element method is discussed in $[17,18]$. Particular developments of the fractional methods are given in Sumelka [19].

In paper by Song and Khalili [20], the elastoplastic constitutive model for geomaterials by adapting a representative model for unsaturated soils via the constitutive correspondence principle is formulated. The total stress is adjusted by a constant value for its possible extension to coupled poromechanical problems. With the effective force vector state, a version of an elastoplastic model for geomaterials formulated in the framework of critical state soil mechanics through the constitutive correspondence principle in the statebased peridynamics. The numerical results show that the proposed constitutive model can be used to model the inception and propagation of shear banding with no need for regularization. Furthermore, the numerical results demonstrate that the variable can be used to characterize the thickness of shear banding zone.
Foster et al. [21] incorporated a viscoplasticity model within the state-based peridynamics framework. Sun and Huang [22] used the peridynamics theory to study impact damage in composite materials. The plastic deformation due to high-velocity impact using ordinary state-based peridynamic theory is presented in the paper by Kazemi [23]. In the paper by Wang et al. [24] a non-ordinary state-based peridynamic formulation for thermo-visco-plastic deformation and impact fracture is applied.

A novel continuum-kinematics-inspired approach for peridynamics and revisited peridynamics thermodynamic foundations are presented by Javili et al. [16]. The related approach is bridging the gap between classical continuum thermodynamics and peridynamics. They propose the peridynamics formulation whose underlying concepts are reminiscent of classical continuum mechanics. In particular, they propose to decompose the interaction potentials into three parts corresponding to one-neighbour interactions, twoneighbour interactions and three-neighbour interactions within the horizon. One-neighbour interactions are identical to bond-based interactions in the peridynamics formulation of Piola (dell'Isola et al. [25]) and Silling [26]. Javili et al. [27] derive the balance of linear and angular momentum corresponding to our interaction potentials and identify the fundamental properties of these potentials such that angular momentum balance is a priori fulfilled and propose thermodynamically consistent constitutive laws.

The classical bond-based peridynamic model is limited due to a fixed Poisson's ratio. To overcome this limitation, an improved bond-based peridynamic model is proposed in the paper by Zheng et al. [28]. Zheng et al. analyse the deformation and crack propagation of microelastic brittle materials emphasising varying Poisson's ratios. In the proposed model, the bond is subjected to axial and transverse pairwise forces, and the particle rotation angle is added to eliminate the additional bending moment caused by transverse forces, which is a key factor to satisfy the balance of angular momentum exactly. As a result, the bond has not only axial displacement but also has transverse displacement and particle rotation. This extension in the displacement mode overcomes the limitation of the fixed Poisson's ratio in the classical peridynamic model. Lee et al. [29] develop a numerical scheme to model contact and impact between a peridynamic domain and a non-peridynamic domain 
such as conventional finite elements and rigid bodies. In this paper, the contact is modelled as a node-tosurface type, and a penalty method is used for transient analyses by the explicit time integration. Therefore, the computational burden of the proposed numerical scheme might be reduced. A quantitative study by Lee et al. [29] of ballistic perforation using the proposed numerical scheme and the simulation results show good agreement with the experimental measurements and the analytical calculation of residual velocities.

The subject of the study presented in the paper is the deformation of open-cell copper foams as an example of cellular materials under dynamic compression. The skeleton structure of the cellular material is considered as virtual material with geometry and topology generated by tomographic images of polyurethane foams, produced by Stręk [30]. The geometry of the virtual material skeleton was obtained with use of the reconstruction methodology presented in Nowak et al. [31] and applied for metallic foams by Pęcherski et al. [32]. The skeleton material is assumed as the oxygenfree high conductivity OFHC copper and can be rescaled according to requirements. The OFHC copper powder can be applied in additive manufacturing to produce open-cell multifunctional structures, e.g., crush-resistant heat exchangers, heat capacitors, etc. In the presented peridynamic computations the foam skeleton material is described using an elastic-plastic model with isotropic hardening. The dynamic process of compression and crushing during impact is simulated. In Pęcherski et al. [32], the elastic-viscoplastic model with Huber-Mises-Hencky quasi-static yield criterion was used. The experimental data of the strain-rate dependency of yield strength reveal the plateau within the range of strain-rates between $10^{-4} s^{-1}$ and $10^{3} s^{-1}$ of rather small influence of strain-rate with the rapid growth of yield limit for higher strain-rates, cf. Fig. 7 in Pęcherski et al. 2017. Such a behaviour is characteristic for $f c c$ metals, and in particular for copper. In the paper by Postek et al. [33], the elastic-plastic rate-independent model is assumed to simplify the peridynamic simulations of crushing processes and reduce the computational costs.

The paper is organized as follows. Section 2 presents a problem statement with the presentation of the constitutive law adjusted to peridynamics format. Section 3 presents the example of Taylor impact test of solid circular bar with the assumed viscoplasticity model and material properties, and Sect. 4 describes copper open-cell foam sample analysis. Section 5 provides conclusions.

\section{Problem statement}

An outline of the peridynamics method is shown below. It is presented state-based peridynamics $[3,34,35]$. The application is narrowed to the Huber-Mises-Hencky plasticity [36]. It is applied to the rate-dependent model [21].

The dynamic equation of equilibrium reads:

$$
\rho \ddot{\mathbf{u}}[\mathbf{x}, t]=\nabla \cdot \boldsymbol{\sigma}^{\mathrm{I}}[\mathbf{x}, t]+\mathbf{b}[\mathbf{x}, t]
$$

where $\rho$ is the material density, $\mathbf{u}$ is the displacement vector, $\boldsymbol{\sigma}^{\mathrm{I}}$ is the first Piola-Kirchhoff stress tensor, and b is the body force vector. Equation (1) is determined at the position $\mathbf{x}$ of the body $\Omega$ at time $t$, Fig. $1 \mathrm{a}$.

The state-based peridynamic equation of motion reads [3]:

$$
\rho \ddot{\mathbf{u}}[\mathbf{x}, t]=\int_{H}\left\{\mathbf{T}[\mathbf{x}, t]\left\langle\mathbf{x}^{\prime}-\mathbf{x}\right\rangle-\mathbf{T}\left[\mathbf{x}^{\prime}, t\right]\left\langle\mathbf{x}-\mathbf{x}^{\prime}\right\rangle\right\} d V_{x^{\prime}}+\mathbf{b}[\mathbf{x}, t]
$$

In the equation above, Eq. (2), $\mathbf{T}$ is the force-vector state, $\mathbf{x}^{\prime}$ is the position of a point within the body $\Omega$ with respect to $\mathbf{x}$ within the subdomain $H$ of radius $h$. The brackets \langle\rangle , denote the vector on which the state acts.

The discrete form of Eq. (2) reads:

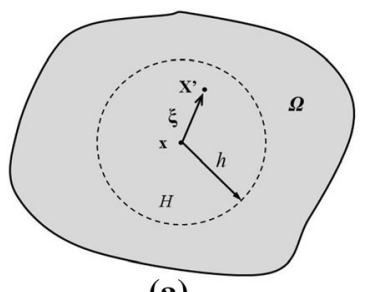

(a)

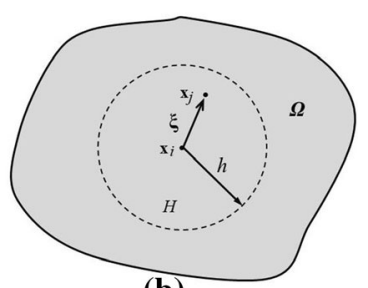

(b)
Fig. 1 Peridynamic body; a continuous representation; b discretized form 


$$
\begin{aligned}
\rho \ddot{\mathbf{u}}\left[\mathbf{x}_{i}, t\right] & \\
= & \sum_{j=1}^{k}\left\{\mathbf{T}\left[\mathbf{x}_{i}, t\right]\left\langle\mathbf{x}_{j}-\mathbf{x}_{i}\right\rangle\right. \\
& \left.-\mathbf{T}\left[\mathbf{x}_{j}, t\right]\left\langle\mathbf{x}_{i}-\mathbf{x}_{j}\right\rangle\right\} V_{j} \\
& +\mathbf{b}\left[\mathbf{x}_{i}, t\right] \quad i=1,2 \ldots n
\end{aligned}
$$

The integral is replaced with a sum of $k$ points within the subdomain $H$, and $n$ is the number of points in the body $\Omega$. The $V_{j}$ is a volume associated with point $j$.

Following Fig. 2, the relative position vector between the points in the undeformed configuration of the body $\Omega$ is denoted by $\xi$. It is given in continuous and discrete forms, Fig. 2a, b, respectively:

$\boldsymbol{\xi}=\mathbf{x}^{\prime}-\mathbf{x}, \quad \xi=\mathbf{x}_{j}-\mathbf{x}_{i}$

The displacement state in its continuous and discrete form is as follows:

$$
\begin{aligned}
\boldsymbol{\eta} & =\mathbf{u}\left[\mathbf{x}^{\prime}, t\right]-\mathbf{u}[\mathbf{x}, t], \\
\boldsymbol{\eta} & =\mathbf{u}\left[\mathbf{x}_{j}, t\right]-\mathbf{u}\left[\mathbf{x}_{i}, t\right]
\end{aligned}
$$

The deformation state reads:

$$
\begin{aligned}
& \mathbf{Y}[\mathbf{x}, t]\langle\xi\rangle \\
& \quad=\mathbf{y}\left(\mathbf{x}_{j}, t\right)-\mathbf{y}\left(\mathbf{x}_{i}, t\right)=\boldsymbol{\xi}+\boldsymbol{\eta}
\end{aligned}
$$

Further on, we will deal with the finite deformation and Huber-Mises-Hencky type of plasticity. The gradient definition is of the following form:

$$
\mathbf{F}=\mathbf{I}+\mathbf{u} \nabla_{\mathbf{x}}
$$

The discrete form of the gradient definition is defined by introducing an influence function $\omega$ [37].

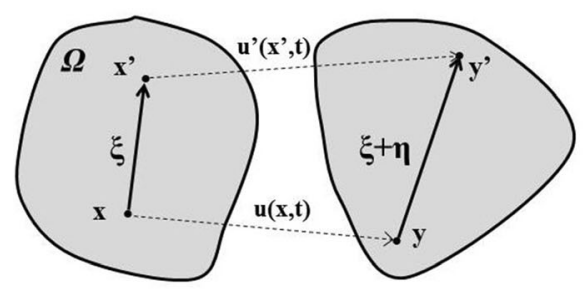

(a)
$\mathbf{F}\left[\mathbf{x}_{i}, t\right] \approx\left[\sum_{j=1}^{k} \omega(|\boldsymbol{\xi}|)(\mathbf{Y}\langle\boldsymbol{\xi}\rangle \otimes \boldsymbol{\xi}) V_{j}\right] \mathbf{K}^{-1}$

The $\mathbf{K}$ is the shape tensor:

$$
\begin{aligned}
& \mathbf{K}\left[\mathbf{x}_{i}, t\right] \\
& \quad \approx \sum_{j=1}^{k} \omega(|\boldsymbol{\xi}|)(\boldsymbol{\xi} \otimes \boldsymbol{\xi}) V_{j}
\end{aligned}
$$

Since the yield condition depends on deviatoric stress, we need both the stress deviator and the deviatoric strain rate evaluated at the unrotated configuration. The deviatoric strain rate is obtained subtracting the volumetric part of the unrotated rate of deformation tensor from the total rate of deformation $\mathbf{d}$ as follows:

$$
\dot{\mathbf{e}}=\mathbf{d}-\frac{1}{3} \operatorname{tr}(\mathbf{d}) \mathbf{I}
$$

The stress deviator depends on unrotated Cauchy stress tensor $\tau$ :

$$
\mathbf{S}=\tau-\frac{1}{3} \operatorname{tr}(\tau) \mathbf{I}
$$

Our goal is to show the relationship between the peridynamic force state $\mathbf{T}$ and the first Piola-Kirchhoff stress tensor. The left and right gradient decomposition into rotation and stretch tensor are of the form [38]

$$
\mathbf{F}=\mathbf{R V}=\mathbf{V R}
$$

The unrotated rate of deformation is of the form:

$$
\mathbf{d}=\mathbf{R}^{\mathrm{T}} \mathbf{D R}
$$

In Eq. (13), $\mathbf{D}$ is obtained from the symmetric decomposition of the spatial velocity gradient $\mathbf{L}$ as follows:

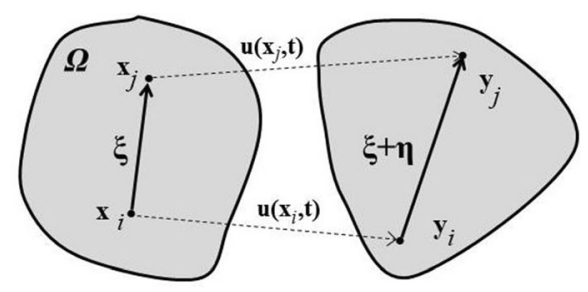

(b)

Fig. 2 The deformation state; a continuous form; $\mathbf{b}$ discrete form 


$$
\begin{aligned}
& \mathbf{L}=\dot{\mathbf{F F}}^{-1}, \\
& \mathbf{D}=\frac{1}{2}\left(\mathbf{L}+\mathbf{L}^{\mathrm{T}}\right)
\end{aligned}
$$

The Cauchy stress tensor $\tau$ is rotated with rotation tensor R:

$$
\tau_{\text {rot }}=\mathbf{R} \tau \mathbf{R}^{\mathrm{T}}
$$

The first Piola-Kirchhoff stress is related to the rotated Cauchy stress tensor by the following relationship:

$$
\boldsymbol{\sigma}^{\mathrm{I}}=\operatorname{det}(\mathbf{F}) \boldsymbol{\tau}_{r o t} \mathbf{F}^{-\mathrm{T}}
$$

The force state is expressed in terms of the first PiolaKirchhoff stress tensor as follows, Silling et al [3]:

$$
\begin{aligned}
& \mathbf{T}\langle\boldsymbol{\xi}\rangle \\
& \quad=\omega(|\boldsymbol{\xi}|) \boldsymbol{\sigma}^{\mathrm{I}} \mathbf{K}^{-1} \boldsymbol{\xi}
\end{aligned}
$$

The deviatoric strain rate is decomposed into its elastic and plastic parts:

$$
\dot{\mathbf{e}}=\dot{\mathbf{e}}^{e}+\dot{\mathbf{e}}^{p}
$$

The elastic and plastic parts of the deviatoric strain rate read:

$$
\dot{\mathbf{e}}^{e}=\frac{\dot{\mathbf{S}}}{2 \mu}, \dot{\mathbf{e}}^{p}=\dot{\lambda} \mathbf{Q}
$$

where $\mu$ is the shear modulus. $\mathbf{Q}$ is the unit tensor normal to the yield surface that comes from the normality condition and $\dot{\lambda}$ is the plastic multiplier. It is assumed that the plastic potential function is equal to the yield function. The assumption defines the associativity of the plasticity condition.

The viscoplastic constitutive law is given in the form that is formulated in $[39,40]$. The flow stress exhibit a strain and strain rate sensitivity and reads:

$$
\begin{aligned}
& \bar{\sigma}(\bar{\epsilon}, \dot{\bar{\epsilon}}) \\
& \quad=\sigma_{y}\left(1+\frac{\bar{\epsilon}}{\bar{\epsilon}_{0}}\right)^{1 / n}\left(1+\frac{\dot{\bar{\epsilon}}}{\dot{\dot{\epsilon}_{0}}}\right)^{1 / m}
\end{aligned}
$$

where $\bar{\sigma} \doteq \sqrt{3 / 2 \mathbf{S}: \mathbf{S}}$ is the equivalent stress with $\mathbf{S}$ being the deviatoric part of the Cauchy stress tensor, $\dot{\bar{\epsilon}} \doteq \sqrt{2 / 3 \dot{\mathbf{e}}^{p}: \dot{\mathbf{e}}^{p}}$ is the equivalent plastic strain rate, $\dot{\bar{\epsilon}}_{0}$ is the reference equivalent plastic strain rate, $\bar{\epsilon} \doteq \int_{t}\left\{\dot{\mathbf{e}}^{p}: \dot{\mathbf{e}}^{p}\right\} d t$ is the equivalent plastic strain and $\bar{\epsilon}_{0}$ is the reference equivalent plastic strain. The $\sigma_{y}$ is the initial yield limit. The exponents $m$ and $n$ are the strain rate coefficient and strain hardening coefficient, respectively. In the analysis of the foam, the strain hardening term is neglected.

According to the energy-based equivalence hypothesis presented in Nowak et al. [41], one can conclude that in two kinds of cellular structures: the periodic one, e.g. of $f c c$ type, and the random one corresponding to foams, the same elastic energy density cumulated in both structures leads to the following assessment of the failure strength of real foam under compression

$$
\begin{aligned}
& \left(\sigma_{f}^{C}\right)_{\text {real }} \\
& \quad=\left(\sigma_{f}^{C}\right)_{f c c} \sqrt{\left(\frac{E_{\text {real }}}{E_{f c c}}\right)}
\end{aligned}
$$

where the failure strength, $\left(\sigma_{f}^{C}\right)$, corresponds in this case to the elastic limit, while $E_{\text {real }}$ and $E_{f c c}$ denote the Young moduli for real and periodic skeleton, respectively. Therefore, accordingly, the subsequent discussion of numerical examples appears valid for a broader class of cellular materials.

\section{Example of Taylor impact test}

\subsection{Model and material properties}

To demonstrate the rate hardening effects, we consider an example of Taylor impact test of solid round bar. The scheme of the structure is given in Fig. 3. The copper cylindrical sample hits a rigid obstacle with an initial velocity.

The length of the bar is $0.0324 \mathrm{~m}$, and the diameter is $0.00032 \mathrm{~m}$. The bar is discretized with 21,000 points. The material parameters of the bar are as follows: Young's modulus is $110 \mathrm{GPa}$, Poisson's ratio is $0.296, \dot{\bar{\epsilon}}_{0}=1.0 \mathrm{E}-031 / \mathrm{s}, \bar{\epsilon}_{0}=0.00218$, yield limit is $50 \mathrm{MPa}$, and material density is $8960 \mathrm{~kg} / \mathrm{m}^{3}$. In this case, the rigid obstacle is modelled, assuming fixed zero displacements along the axis of the bar (zdisplacement) at the impacting surface of the bar. The horizon is assumed $0.0065 \mathrm{~m}$. The structure in Fig. 1a is presented as a set of calculation points surrounded by spheres of radius calculated assuming the volume of the sphere is equal to the hexahedral volumes that 


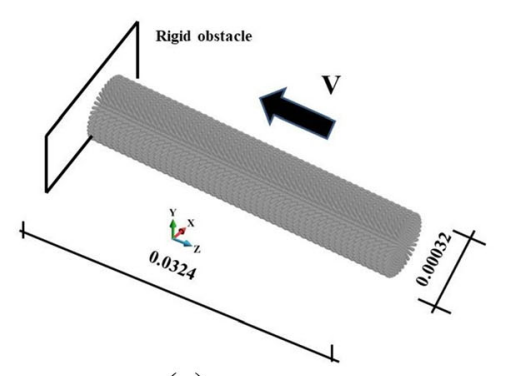

(a)
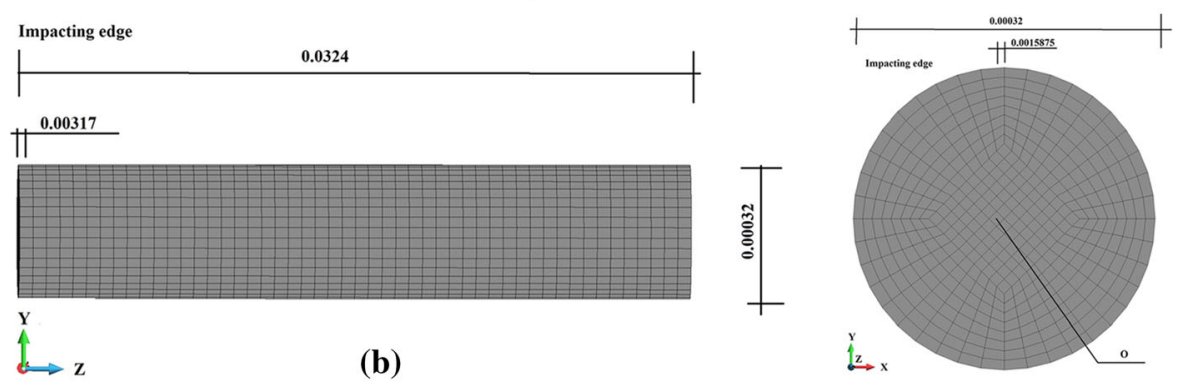

(c)

Fig. 3 Scheme of the impact of the bar (dimensions are in $\mathrm{m}$ ); $\mathbf{a}$ bar with boundary and initial conditions; $\mathbf{b}$ hexahedral grid, distance of the observed point from the impacting edge; $\mathbf{c}$ impacting edge view, position of the observed point $\mathrm{O}$

are shown in Fig. 1b, c. The results are presented on the points-spheres representation.

We consider four cases of material properties. Case A stands for the elastic ideally plastic material. The next three cases concern the increasing strain rate hardening. For $\mathrm{B}, \mathrm{C}$ and $\mathrm{D}$, the strain rate hardening is $0.001,0.01$ and 0.1 . The strain hardening coefficient is 0.1 for all of the cases. The strain rate hardening values are chosen to demonstrate the effect of high, medium and low value of the coefficient. The values of their range are given in industrial applications; see Peirce et al. [42].

The simulations are performed with an Open Access program Peridigm [43-46]. The program is massively parallelized with MPI. It uses the set of libraries Trilinos [47] that provides tools for the equation solving and parallelization. The geometry is prepared using Patran system [48]. Then, the neutral file is transformed into Exodus/Genesis ASCII format, $[49,50]$. The ASCII file is converted into binary one. The binary file is decomposed into calculation domains before the Peridigm execution. The problem definition is given in an $\mathrm{xml}$ file. The results have to be merged into one file using a python script. Then, the results are converted into ASCII file. To visualize the results the GiD program is used [51]. The analysis is done with the explicit integration method. The stable time step is $5.28 \mathrm{E}-07 \mathrm{~s}$. However, it is employed a much lower fixed time step of $6.609 \mathrm{E}-08 \mathrm{~s}$ to observe the process at the same time instants for different testing parameters. The analysis takes $120 \mathrm{~s}$ on a Linux cluster with Intel/Xeon processors E5-2680 v3. It has been applied 2 processors of 24 cores each.

\subsection{Numerical results}

We compare the shapes of the bar at the end of the process. The displacement fields for all of the cases are shown in Figs. 4 and 5.

The series of pictures in Figs. 4 and 5 starts from the elastic-plastic case with no strain rate hardening and ends up with the highest value of the strain rate hardening for Case D. We note that the shape of the sample strongly depends on the strain rate hardening coefficient. In the case of its highest value, there is no visible mushroom-like foot in contrast to the elasticplastic case and the lowest value of the coefficient. The series of shapes are qualitatively similar for both impact velocities, namely $50 \mathrm{~m} / \mathrm{s}$ and $80 \mathrm{~m} / \mathrm{s}$. The 


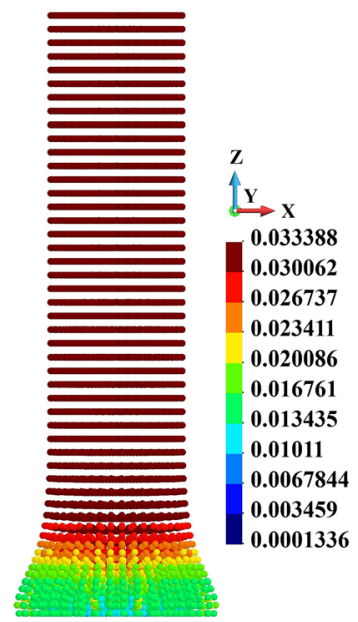

(a)

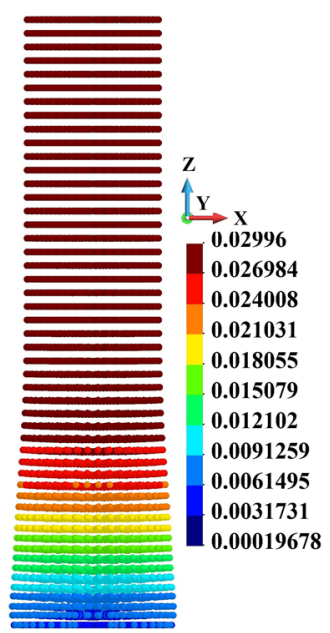

(c)

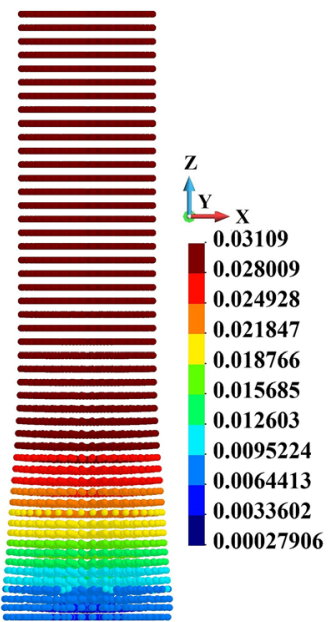

(b)

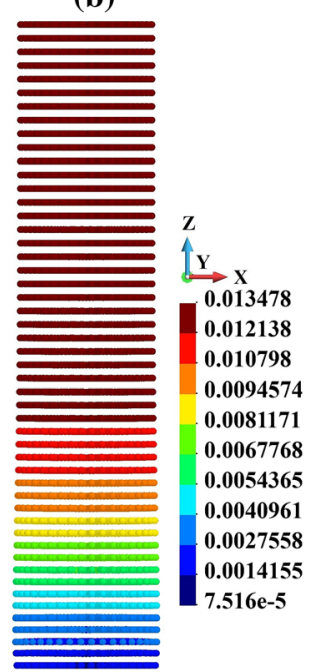

(d)

Fig. 4 Shape of the bar, impact velocity $50 \mathrm{~m} / \mathrm{s}$; a Case A; b Case B; c Case C; $\mathbf{d}$ Case D

values of the maximum displacements are collected in Tables 1 and 2. The difference between the case without rate hardening and with a low value of rate hardening for lower impact velocity is $59.6 \%$ and $50.8 \%$ for higher impact velocity. The equivalent plastic strain distribution at the end of the process is shown in Figs. 6 and 7. The distributions that are shown in both Figs. 6 and 7 are qualitatively similar. It means they are similar for both impact velocities. However, the picture is different for particular cases of the strain rate hardening coefficient. In the case of elastic-plastic example without strain hardening, the base of the sample shows significant effect of

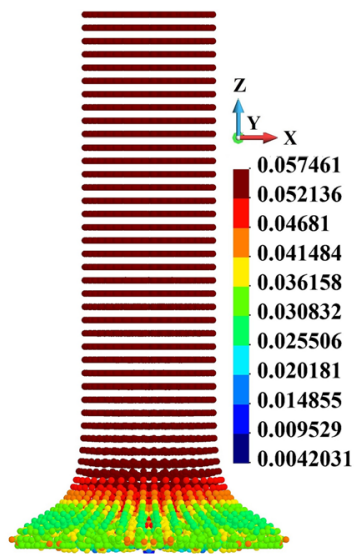

(a)

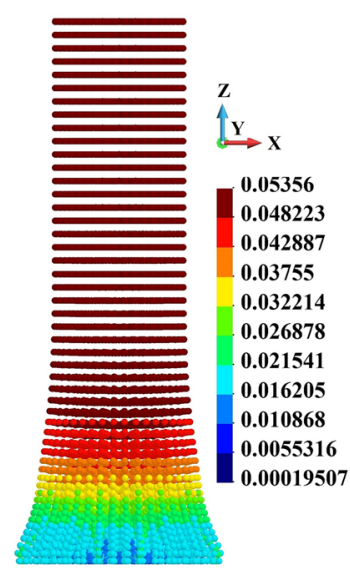

(c)

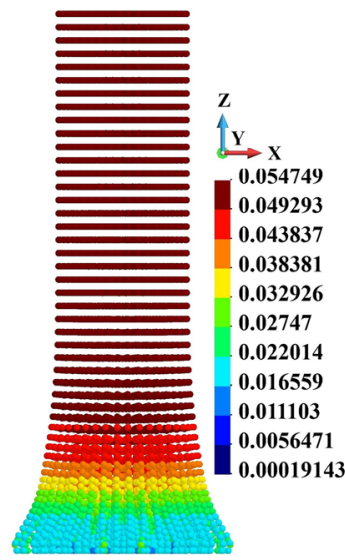

(b)

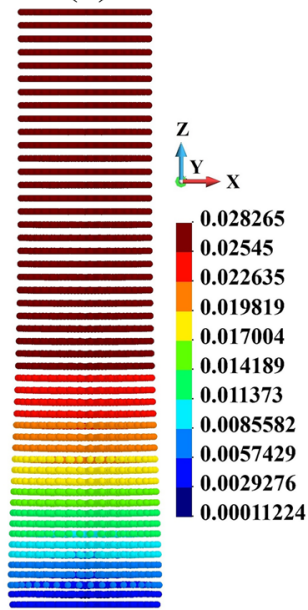

(d)
Fig. 5 Shape of the bar, impact velocity $80 \mathrm{~m} / \mathrm{s}$; a Case A; b Case B; c Case C; d Case D

mushrooming, Figs. 6a and 7a. The equivalent plastic strain can be considered as smeared on the surface of of the bar's deformed base but the equivalent plastic strain is the highest close to the centre of the base. The cases of high and moderate values of the coefficient, namely Figs. $6 \mathrm{~b}, \mathrm{c}$ and $7 \mathrm{~b}, \mathrm{c}$ are qualitatively similar to Case A. They are more similar to Case A when the sample undergoes higher impact velocity when observing the shape of the developed foot of the sample and the equivalent plastic strain distribution. The Case D is qualitatively different from Cases A, B and C. Namely, the foot is practically not developed, and the equivalent plastic strain is high in the middle of the base of the sample and close to the outer surface of the sample, Figs. $6 \mathrm{~d}$ and $7 \mathrm{~d}$. 
Table 1 Values at the end of the process, impact velocity $50 \mathrm{~m} / \mathrm{s}$

\begin{tabular}{lllll}
\hline Case & \multicolumn{1}{c}{ A } & B & C & D \\
\hline Displacements (m) & 0.0334 & 0.0311 & 0.0299 & 0.0135 \\
Equivalent plastic strain & 1.308 & 0.664 & 0.576 & 0.163 \\
HMH stress $(\mathrm{Pa})$ & $5.0 \mathrm{E}+07$ & $8.813 \mathrm{E}+07$ & $9.252 \mathrm{E}+07$ & $1.577 \mathrm{E}+08$ \\
\hline
\end{tabular}

Table 2 Values at the end of the process, impact velocity, impact velocity $80 \mathrm{~m} / \mathrm{s}$

\begin{tabular}{lllll}
\hline Case & \multicolumn{1}{c}{$\mathrm{A}$} & $\mathrm{B}$ & $\mathrm{C}$ & $\mathrm{D}$ \\
\hline Displacements (m) & 0.0575 & 0.0547 & 0.0536 & 0.0283 \\
Equivalent plastic strain & 2.272 & 1.686 & 1.500 & 0.371 \\
$\mathrm{HMH}$ stress $(\mathrm{Pa})$ & $5.0 \mathrm{E}+07$ & $9.854 \mathrm{E}+07$ & $1.085 \mathrm{E}+08$ & $1.630 \mathrm{E}+08$ \\
\hline
\end{tabular}

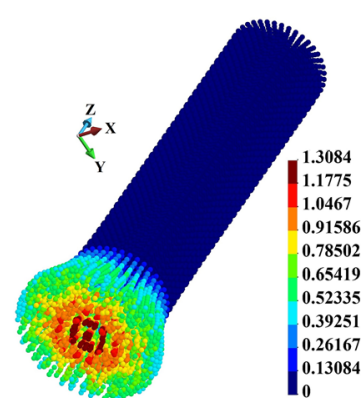

(a)

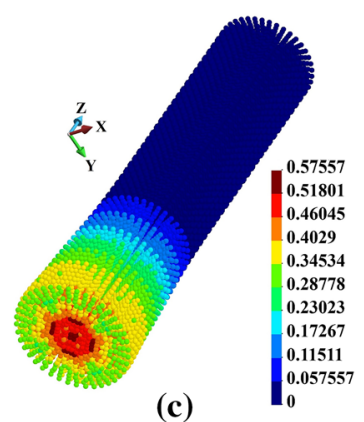

(c)

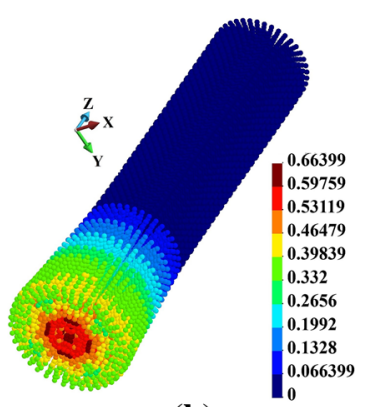

(b)

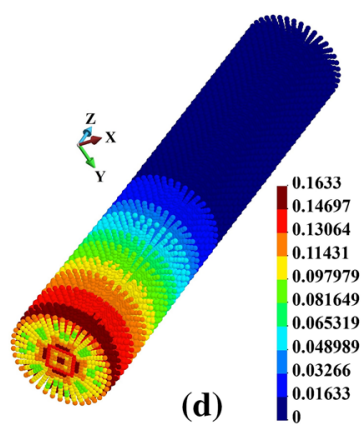

(d)

Fig. 6 Equivalent plastic strain distribution, impact velocity 50 $\mathrm{m} / \mathrm{s} ;$ a Case A; b Case B; c Case C; d Case D

Further on, we analyse the variation in time of the equivalent plastic strain at the observed point $\mathrm{O}$. The point is located in the middle of the cross-section of the bar at 3.17E-03 $\mathrm{m}$ from its base. We note that for both impact velocities, the curves are qualitatively similar, Fig.8. When concerning the elastic-plastic without strain hardening (Case A), the variation is

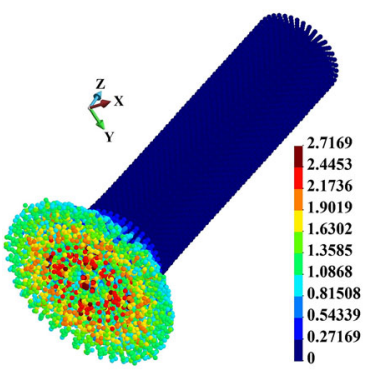

(a)

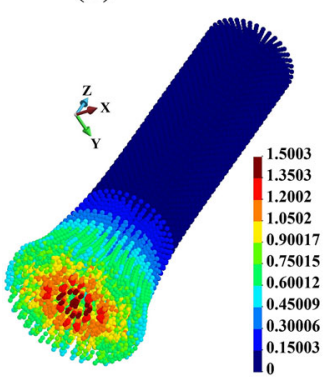

(c)

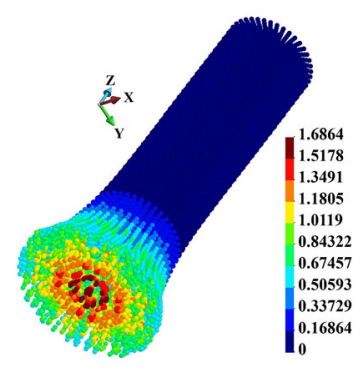

(b)

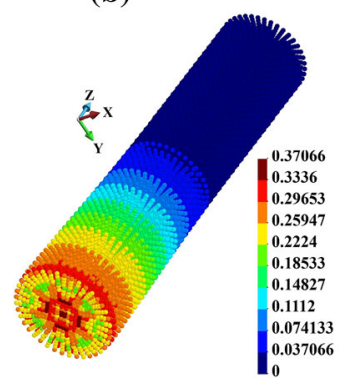

(d)
Fig. 7 Equivalent plastic strain distribution, impact velocity 50 $\mathrm{m} / \mathrm{s} ;$ a Case A; b Case B; c Case C; $\mathbf{d}$ Case D

practically linear throughout the process. In the cases with strain hardening, the variations tend to stabilize at certain levels indicated in Tables 1 and 2.

The maximum equivalent plastic strain dependence on the strain hardening coefficient is given in Fig. 9. We find that the dependence is not linear. The difference between the high and low values of the 


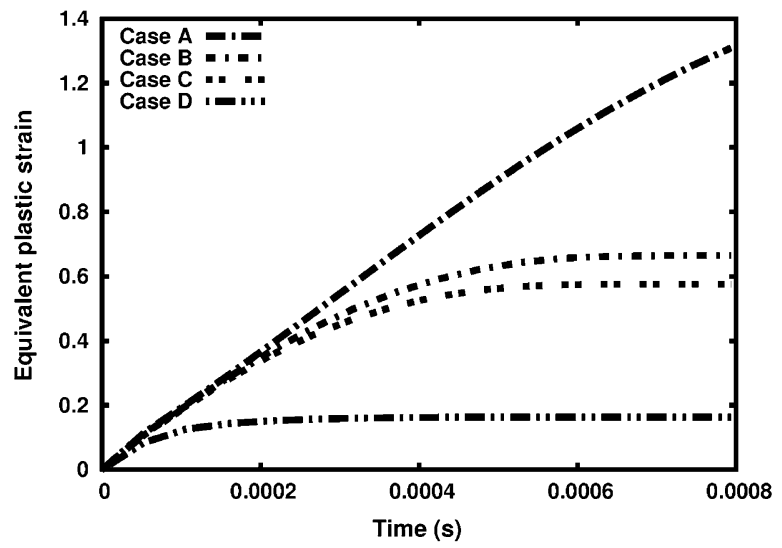

(a)

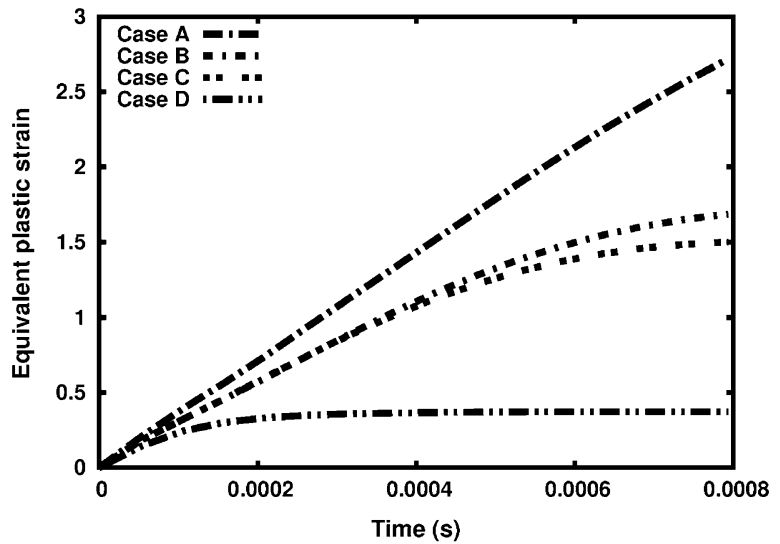

(b)

Fig. 8 Equivalent plastic strain variation in time at the observed point; a impact velocity $50 \mathrm{~m} / \mathrm{s} ; \mathbf{b}$ impact velocity $80 \mathrm{~m} / \mathrm{s}$

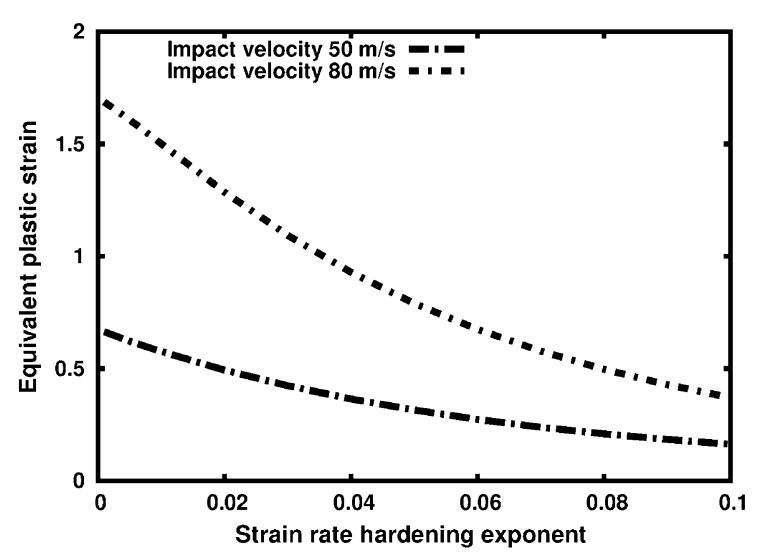

Fig. 9 Maximum equivalent plastic strain in the sample at the end of the process, the dependence on strain rate hardening coefficient; a impact velocity $50 \mathrm{~m} / \mathrm{s}$; b impact velocity $80 \mathrm{~m} / \mathrm{s}$

equivalent plastic strain for the two impact velocities is much higher for the low values of the coefficient than for the high one. The percentage difference reads $154 \%$ and $127 \%$, respectively.

The maximum Huber-Mises-Hencky stress at the end of the process strongly depends on the rate hardening coefficient. The values are collected in Tables 1 and 2. The highest stress is reached when the strain rate hardening coefficient is the highest, namely, in the Case of $\mathrm{D}$, for both impact velocities. The differences between Cases B and D for the impact velocity $50 \mathrm{~m} / \mathrm{s}$ an $80 \mathrm{~m} / \mathrm{s}$ are $44 \%$ and $39 \%$, respectively. To summarize, the rate hardening coefficient is vital for the behaviour of the sample. Its value affects the shape of sample strongly, maximum equivalent plastic strain and Huber-Mises-Hencky stress.

\section{Copper foam sample analysis}

\subsection{Model and material properties}

We analyse the impact of a copper foam sample into an ideally elastic block. The scheme of the analysed system is given in Fig. 10. The foam is represented by tetrahedral volumes while the foam is represented by hexahedrals. It is shown in Fig. 10b, c. The copper foam sample hits the elastic obstacle with an initial velocity. Similarly to the considered example of Taylor impact test of solid bar the numerical model consists of set of points surrounded by spheres. It is shown in Fig. 11. The results are presented on pointsspheres representation.

The dimensions of the foam sample are $0.0025 \times 0.0025 \times 0.0025 \mathrm{~m}$. The plate is of the dimensions $0.0035 \times 0.0035 \times 0.001 \mathrm{~m}$. The sample hits the plate with initial velocities of $20 \mathrm{~m} / \mathrm{s}$ and $40 \mathrm{~m} /$ $\mathrm{s}$, respectively. The plate is discretized with $1,600,000$ points, and the foam skeleton is discretized with $2,651,427$ points. The material properties of the foam skeleton are the same as those of the cylindrical bar considered in the Taylor test. The plate is ideally elastic of the material properties as follows: Young's modulus is $210 \mathrm{GPa}$, Poisson's ratio is 0.296 and material density is $8960 \mathrm{~kg} / \mathrm{m}^{3}$. The process is followed up to $0.095 \mathrm{E}-08 \mathrm{~s}$. The explicit time 


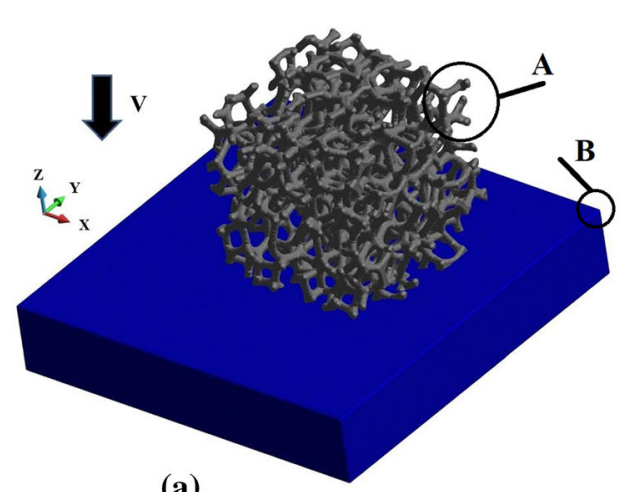

(a)

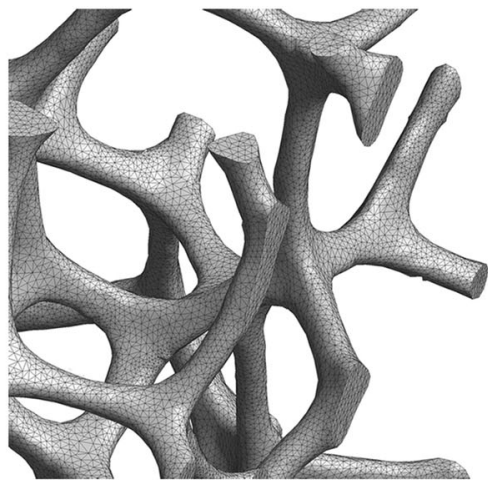

(b)

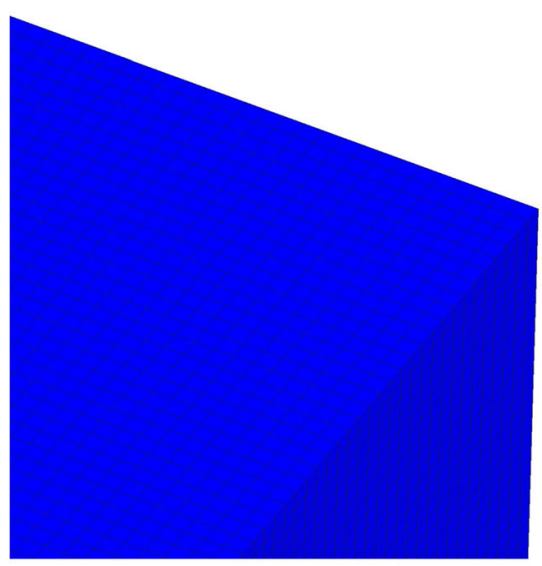

(c)

Fig. 10 Impacting foam sample, basic volume discretized geometry; a scheme; b detail A; c detail B

stepping is used. The stable time increment is $2.8 \mathrm{E}-09 \mathrm{~s}$. However, the fixed time incrementation is used. The time step is $2.0 \mathrm{E}-09 \mathrm{~s}$. The plate is fixed at its bottom surface. The general contact conditions are assumed. It means that the searching for contact is between all outer surfaces of the bodies. It includes the self-contact as well. The penalty formulation is employed. The contact force is computed based on a short-range formulation $[43,45,52,53]$. The contact force reads:

$f_{\text {cont }}$

$$
=\left\{\begin{array}{cl}
K_{\text {cont }}\left(r_{\text {cont }}-d\right) V_{1} V_{2} & \text { for } d \leq r_{\text {cont }} \\
0 & \text { for } d>r_{\text {cont }}
\end{array}\right.
$$

In Eq. (22), $K_{\text {cont }}=18 K_{p} /\left(\pi h^{5}\right)$ where $K_{p}$ is the penalty number (spring stiffness) that replaces the bulk modulus in the spring constant [52], $r_{\text {cont }}$ is the contact radius, and $d$ is the distance between the calculation points. The penalty number is assumed
$1.0 \mathrm{E}+12$, and the contact radius is $55.0 \mathrm{E}-06 \mathrm{~m} . V_{1}$ and $V_{2}$ are the volumes of the corresponding points in contact and $d$ is the distance between them. The horizon is assumed $50.0 \mathrm{E}-06 \mathrm{~m}$.

In non-local methods, the boundary conditions appear non-local as well. The problem for gradient methods has been discussed in $[54,55]$. As in the gradient methods that are described above, the effect of boundary is propagated into the considered domain [3]. The problem is solved by the PALS model (Position Aware Linear Solid) [56] employing the surface correction. However, in the report [57], it has been shown that the effect of the free surface diminishes when employing fine discretization. The discretization of each branch of the foam, Fig. 11, is close to or finer than the case $N=7$ (slide 4 in [57]). The effect of the boundary diminishes.

As in the Taylor impact test example, we assume four cases of the material properties. Case A stands for 


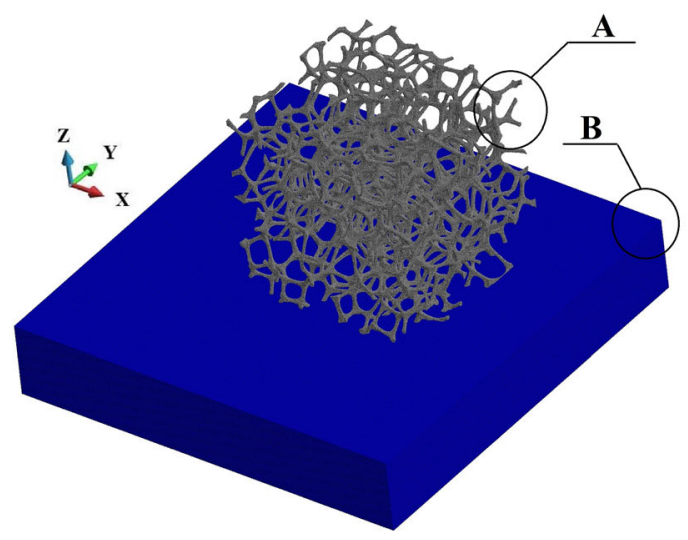

(a)

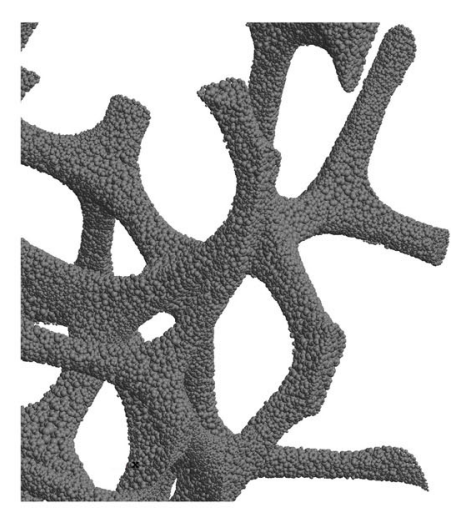

(b)

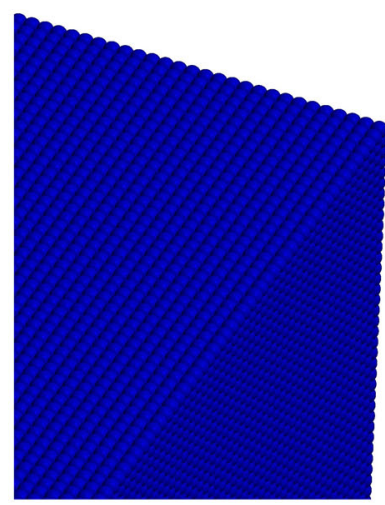

(c)

Fig. 11 Impacting foam sample, points-spheres representation; a entire structure; b detail A; c detail B

the elastic, ideally plastic material. As in the previous consideration, we take into account three further cases, namely, cases B, C and D of the strain rate hardening $0.001,0.01$ and 0.1 , respectively. The strain hardening effect is neglected. As previously, the strain rate hardening is chosen to demonstrate the effect of the low, medium and high value of the coefficient.

In this case, the geometry of the foam is taken from CT (Computed Tomography) scans that are converted into finite element mesh. The CT scans are transformed into a basic tetrahedral mesh with ScanIP+FE [58]. Then, the basic mesh is processed using GiD [51] and GMSH [59] programs. Employing the GiD program, an outer triangular surface mesh is taken, so-called 'skin'. Further, using the GMSH program, a new refined tetrahedral mesh is obtained. The new mesh is converted into the Exodus/Genesis ASCII format as in the Taylor test example. The rest steps are the same as in the latter case. The GiD program is used for the post-processing of the results.

The analysis is carried out on the same cluster as the Taylor test example. It is used 40 processors with 24 cores each. A run requires about $5100 \mathrm{~s}$. The value varies slightly due to the level of engagement of the cluster with other tasks.

\subsection{Numerical results}

We compare the equivalent plastic strain and $\mathrm{HMH}$ stress distributions. The equivalent plastic strain distributions for all of the considered cases are shown in Figs. 14 and 15. The highest equivalent plastic strain appears when the material is assumed elastic-plastic, Figs. 12a and 13a. When the strain rate coefficient increases what is represented by Cases B, C and D, the maximum equivalent plastic strain decreases. The 


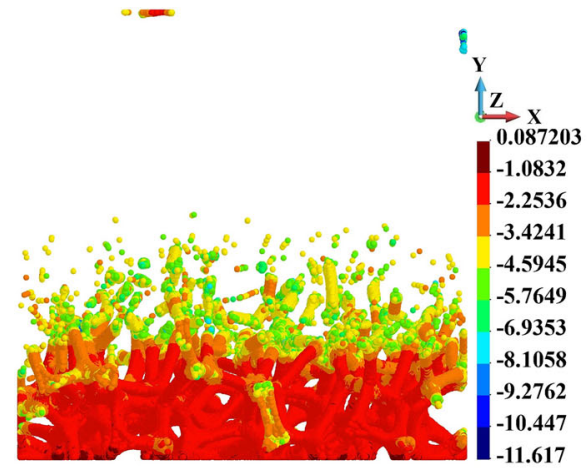

(a)

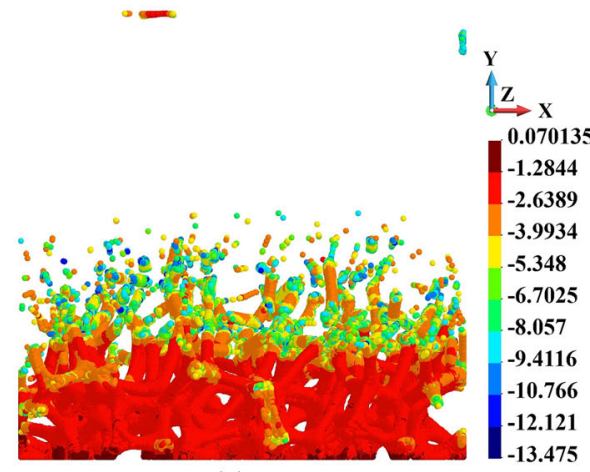

(c)

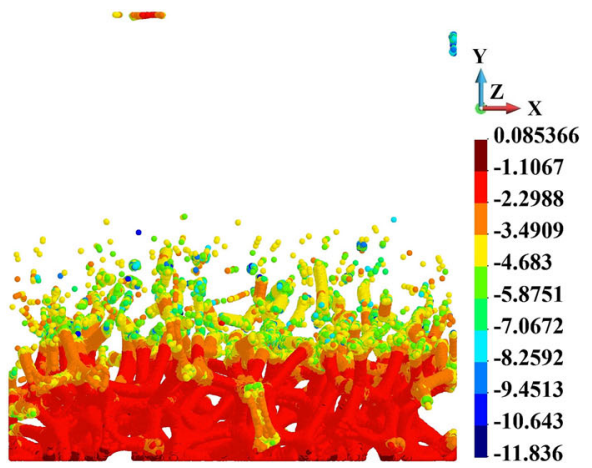

(b)

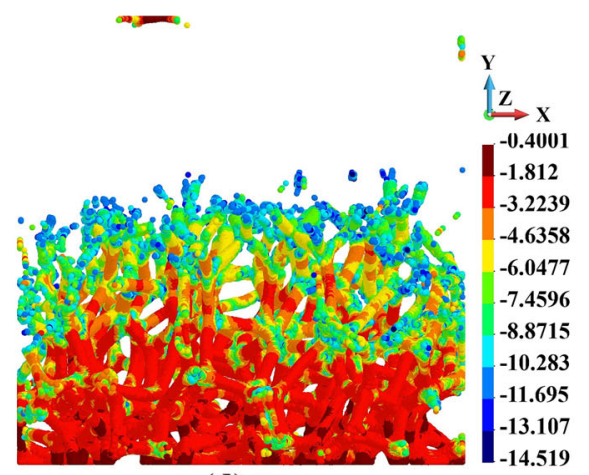

(d)

Fig. 12 Equivalent plastic strain (logarithmic scale), impact velocity $20 \mathrm{~m} / \mathrm{s}$; a Case A; b Case B; c Case C; d Case D

relevant values are given in Tables 3 and 4. From the qualitative analysis of the subsequent results in Figs. 12 and 13, we note that even though the maximum equivalent plastic strain decreases, the extent of the equivalent plastic strain in the structure increases. It happens in the case of both impact velocities.

Further on, we follow the HMH stress distribution. The maximum values for both impact velocities are collected in Tables 3 and 4. The maximum $\mathrm{HMH}$ stress depends on the strain rate coefficient, significantly, reaching 10 times the yield stress. When observing Figs. 14 and 15, we note that the elasticplastic case (Case A) is very similar to Case B that is the lowest strain rate coefficient, Figs. 14a, b (lower impact velocity) and Figs. 15a, b (higher impact velocity). The picture is different in Cases $C$ and $D$ for both impact velocities, Figs 14c, d and 15c, d. We observe that the extent of the high HMH stress is similar, but in Case $\mathrm{C}$, the region of higher stress (red colour and colours closer to upper part of the scale) that value is closer to the maximum stress is much more extended than in Case D. In Case D, the pictures are dominated by the colours from midscale of the palette. It means that the highest stress is concentrated.

The points where the highest equivalent plastic strain appears are located at the bottom of the foam sample, Fig. 16. The positions are different in the case of different impact velocities. The locations depend on the complex shape of the structure. In the case of the impact velocity $20 \mathrm{~m} / \mathrm{s}$, we identify two such points $(\mathrm{K}, \mathrm{L})$, and in the case of the higher impact velocity, one point is identified (M).

In the case of the lower impact velocity, the plots of the equivalent plastic strain variation in time are given in Fig. 17. We note that the strain rate hardening coefficient's influence starts to be significant for its higher values, namely, in Case D. In Fig. 17, Case B is omitted since it is close to the elastic-plastic case. The curves for Cases A and B are practically overlapped. In the case of higher strain hardening coefficient, the increase of the equivalent plastic strain stabilizes that 
Fig. 13 Equivalent plastic strain (logarithmic scale), impact velocity $40 \mathrm{~m} / \mathrm{s}$; a Case A; b Case B; c Case C; $\mathbf{d}$ Case D

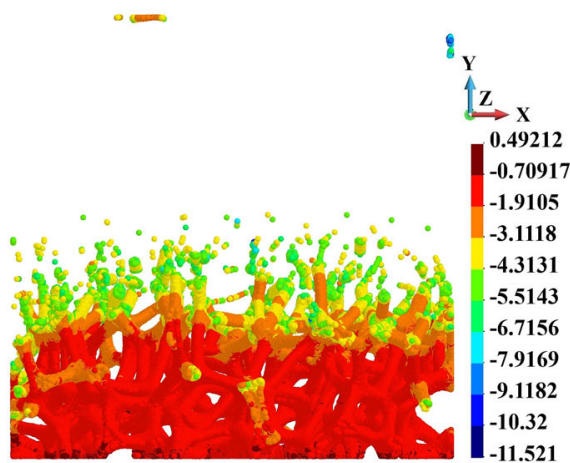

(a)

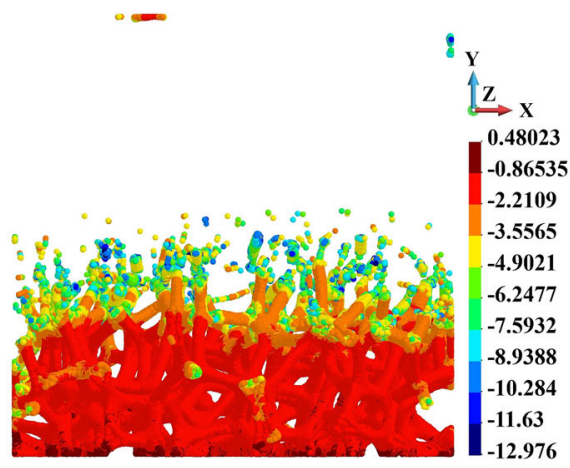

(c)

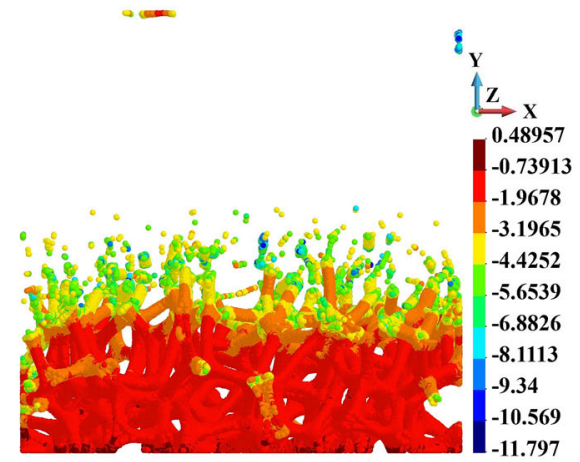

(b)

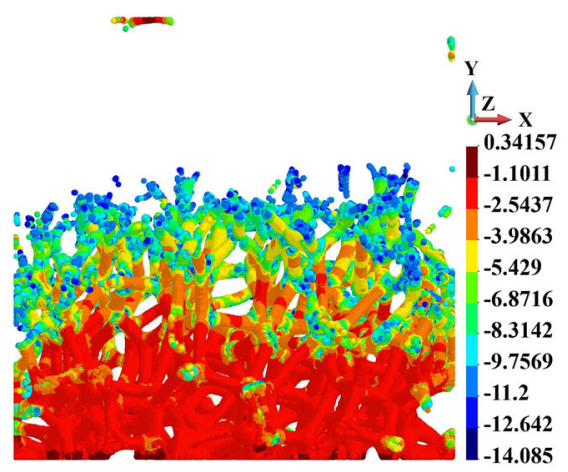

(d)

Table 3 Values at the end of the process, impact velocity $20 \mathrm{~m} / \mathrm{s}$

\begin{tabular}{lllll}
\hline Case & \multicolumn{1}{c}{$\mathrm{A}$} & \multicolumn{1}{c}{$\mathrm{B}$} & \multicolumn{1}{c}{$\mathrm{C}$} & \multicolumn{1}{c}{$\mathrm{D}$} \\
\hline Displacements (m) & 0.00011439 & 0.00011377 & 0.00011377 & $5.8073 \mathrm{E}-05$ \\
Equivalent plastic strain & 1.2224 & 1.2172 & 1.1753 & 0.39801 \\
HMH stress (Pa) & $5.0 \mathrm{E}+07$ & $5.1054 \mathrm{E}+07$ & $6.1761 \mathrm{E}+07$ & $4.8227 \mathrm{E}+08$ \\
\hline
\end{tabular}

Table 4 Values at the end of the process, impact velocity $40 \mathrm{~m} / \mathrm{s}$

\begin{tabular}{lllll}
\hline Case & \multicolumn{1}{c}{$\mathrm{A}$} & \multicolumn{1}{c}{$\mathrm{B}$} & \multicolumn{1}{c}{$\mathrm{C}$} & \multicolumn{1}{c}{$\mathrm{D}$} \\
\hline Displacements (m) & 0.0002408 & 0.0002403 & 0.00023426 & 0.00016017 \\
Equivalent plastic strain & 3.1054 & 3.0872 & 3.0215 & 2.1957 \\
HMH stress (Pa) & $5.0 \mathrm{E}+07$ & $5.1042 \mathrm{E}+07$ & $6.2237 \mathrm{E}+07$ & $4.829 \mathrm{E}+08$ \\
\hline
\end{tabular}

is in contrast to Cases $\mathrm{A}, \mathrm{B}$ and $\mathrm{C}$, where the equivalent plastic strain grows monotonically. When considering the higher impact velocity, the observations are the same as in the case of the lower impact velocity. However, the values of the maximum equivalent plastic strain are higher, Fig. 18a.
The dependence of maximum values of the equivalent plastic strain at the end of the process on the strain hardening coefficient is depicted in Fig. 18b. Approximately, we note a linear decrease of the maximum equivalent plastic strain in the structure for 


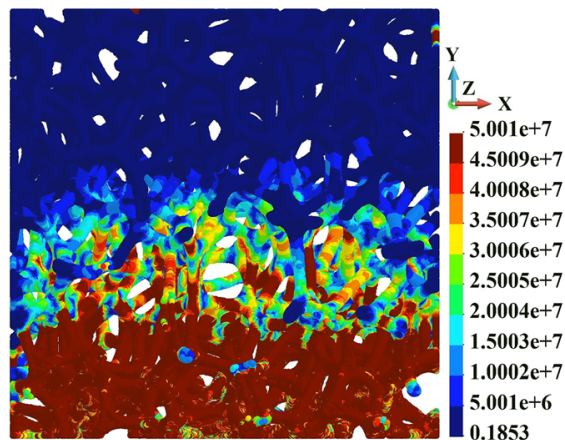

(a)

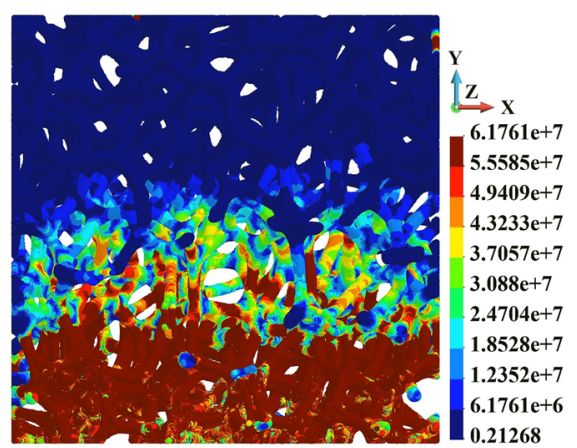

(c)

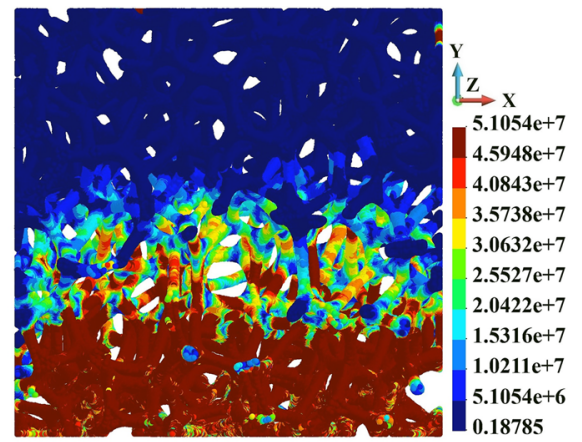

(b)

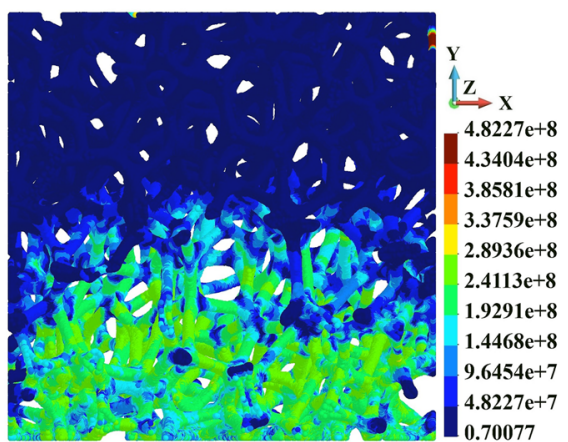

(d)

Fig. 14 Huber-Mises-Hencky stress distribution, impact velocity 20 m/s; a Case A; b Case B; c Case C; d Case D

Fig. 15 Huber-MisesHencky stress distribution, impact velocity $40 \mathrm{~m} / \mathrm{s}$; a Case A; b Case B; c Case C; $\mathbf{d}$ Case D

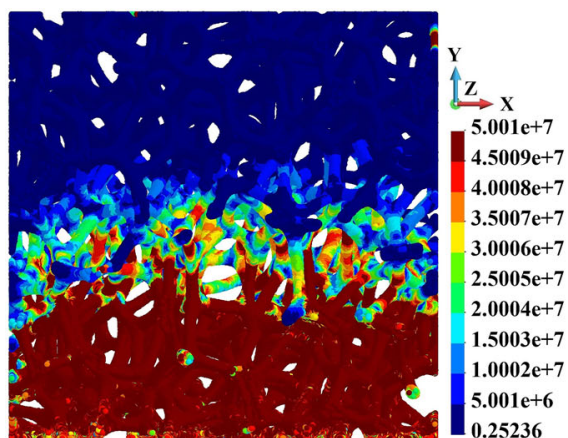

(a)

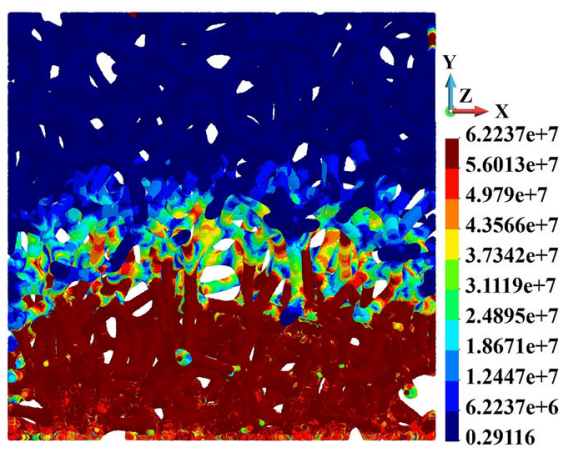

(c)

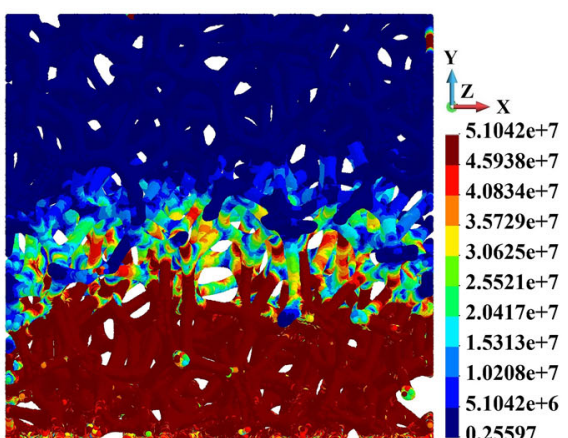

(b)

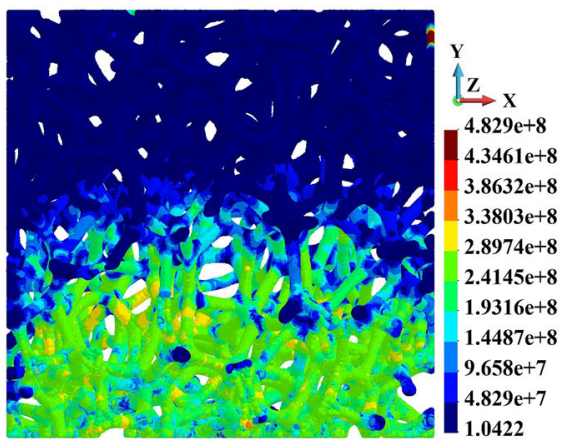

(d) 
Fig. 16 Positions of the observed points at the bottom of the sample (dimensions are multiplied by $1.0 \mathrm{E}-04 \mathrm{~m})$; a impact velocity $20 \mathrm{~m} / \mathrm{s} ; \mathbf{b}$ impact velocity $40 \mathrm{~m} / \mathrm{s}$

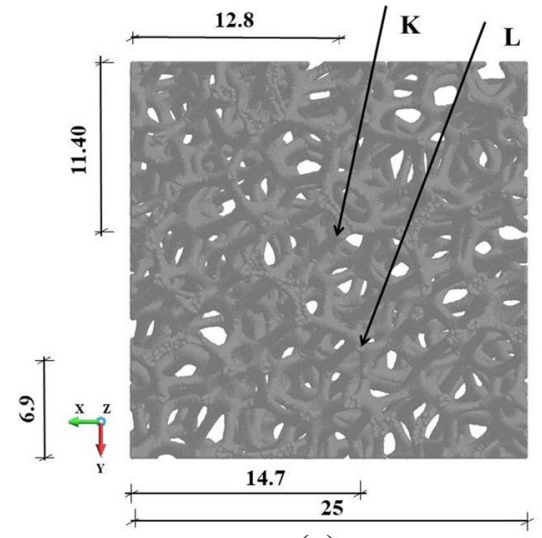

(a)

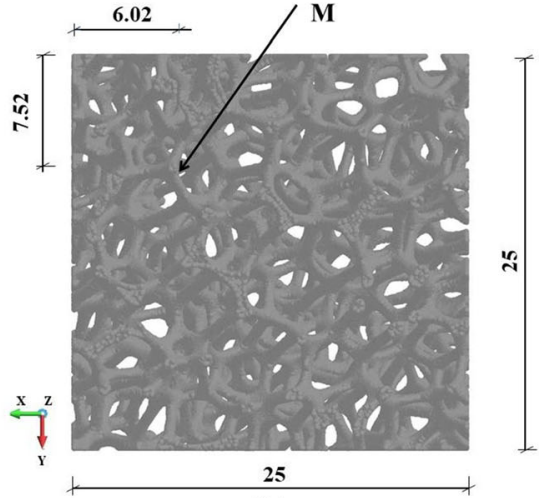

(b)

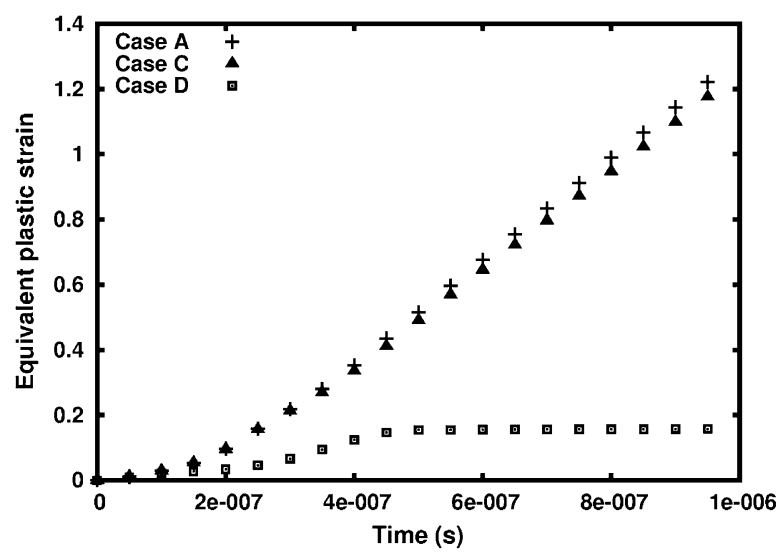

(a)

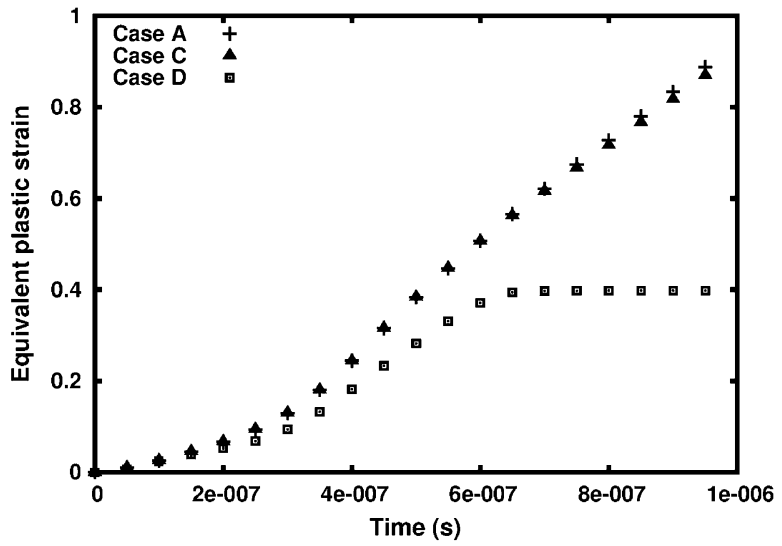

(b)

Fig. 17 Equivalent plastic strain dependence on time at the observed points (in Fig. 16), impact velocity 20 m/s; a Point K; b Point L

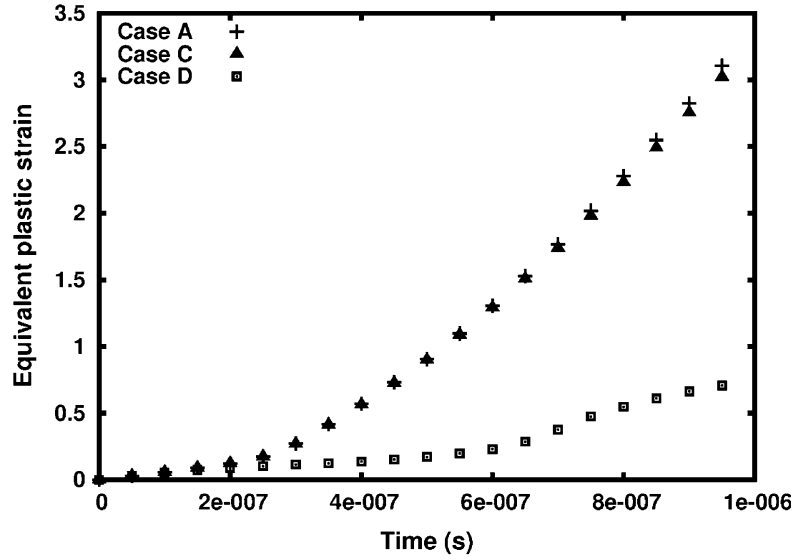

(a)

Fig. 18 Equivalent plastic strain dependence on time at the observed point $\mathrm{M}$ (in Fig. 16), impact velocity $40 \mathrm{~m} / \mathrm{s}$ (a); Maximum equivalent plastic strain in the sample at the end of

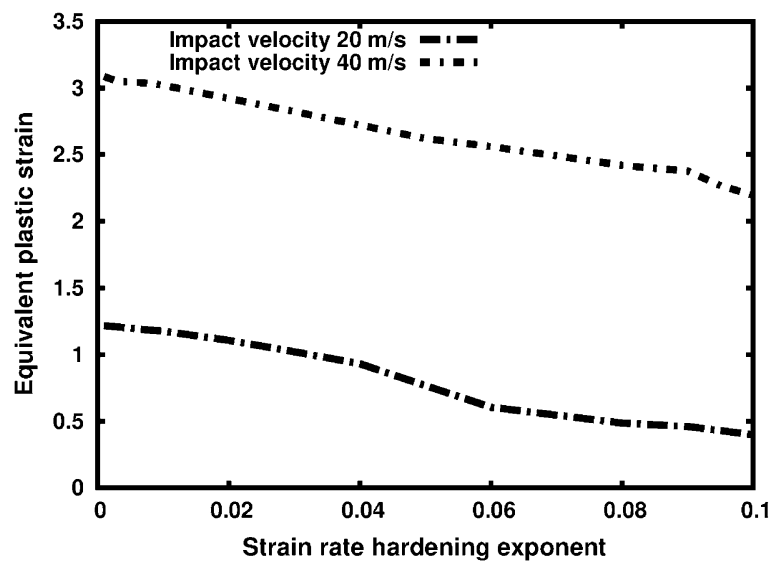

(b)

the process, the dependence on the strain rate hardening coefficient, impact velocity $20 \mathrm{~m} / \mathrm{s}$ and $40 \mathrm{~m} / \mathrm{s}$ (b) 
both impact velocities and the strain rate hardening coefficient's interval.

\section{Conclusions}

We investigated the influence of strain rate hardening coefficient on the behaviour of a copper foam that is under impact conditions. The analysis precedes an introductory example of the Taylor test impact bar. The observations could be collected in the following points:

- the strain rate hardening effect is vital for the behaviour of the structure,

- an increase of the strain hardening coefficient causes a decrease of maximum equivalent plastic strain in the sample, however the extent of plastic zone is larger,

- the maximum HMH stress increases in the sample when the strain rate hardening coefficient increases,

- when the strain rate hardening effect is stronger the HMH stress is more concentrated than in the opposite case.

The presented study contains preliminary results of the virtual cellular material analysis with the assumed skeleton of OFHC copper. The investigations were conducted as numerical simulations of quasi-static and dynamic loading processes. The peridynamics computations provide a convenient and versatile method of repeating numerical experiments. It is in accord with the point of view presented by Zohdi and Wriggers [60]. They stress that making predictions of a new materials behaviour by numerical simulations reduces laboratory expense and accelerates the trial and error laboratory development of new materials.

The elaborated virtual cellular material analysis provides particular studies on demand preparing the experimental investigations program for functional cellular copper materials. Such a goal finds industrial confirmation for copper foam has excellent function of conducting heat and electricity. It can be used as the electrode substrate of lithium-ion battery or fuel cell and electric double layer capacitor electrode material. On the other hand, copper foam can also be used as heat sink materials, heat absorption materials, chemical catalyst carriers and electromagnetic shielding materials, as well as damping or deadening materials.

Acknowledgements The calculations were done within PLGRID national computational resources at the Academic Computer Centre Cyfronet at Krakow, Poland and Interdisciplinary Centre for Mathematical and Computational Modelling, University of Warsaw, Poland. The license for the MSC Patran program was provided by Academic Computer Centre in Gdańsk, Poland.

\section{Declaration}

Conflict of interest The authors declare that they have no conflict of interest.

Open Access This article is licensed under a Creative Commons Attribution 4.0 International License, which permits use, sharing, adaptation, distribution and reproduction in any medium or format, as long as you give appropriate credit to the original author(s) and the source, provide a link to the Creative Commons licence, and indicate if changes were made. The images or other third party material in this article are included in the article's Creative Commons licence, unless indicated otherwise in a credit line to the material. If material is not included in the article's Creative Commons licence and your intended use is not permitted by statutory regulation or exceeds the permitted use, you will need to obtain permission directly from the copyright holder. To view a copy of this licence, visit http://creativecommons.org/licenses/by/4.0/.

\section{References}

1. Kunin A (1982) Elastic media with microstructure, one dimensional models. Springer, Berlin

2. Rogula D (1982) Nonlocal theory of material media. Springer, Berlin, pp 124-222

3. Silling SA, Epton E, Weckner O, Xu J, Askari E (2007) Peridynamic states and constitutive modeling. J Elast 88(2):151-184

4. Bobaru F, Duangpanya M (2010) The peridynamic formulation for transient heat conduction. Int $\mathrm{J}$ Heat Mass Tran 53(19-20):4047-4059

5. Oterkus S, Madenci E, Agwai A (2014) Peridynamic thermal diffusion. J Comput Phys 265:71-96

6. Wang Y, Zhou X, Kou M (2019) An improved coupled thermo-mechanic bond-based peridynamic model for cracking behaviors in brittle solids subjected to thermal shocks. Eur J Mech A Solids 73:282-305

7. Song X, Menon S (2019) Modeling of chemo-hydromechanical behavior of unsaturated porous media: a nonlocal approach based on integral equations. Acta Geotech 14(3):727-747

8. Jafarzadeh S, Chen Z, Li S, Bobaru F (2019) A peridynamic mechano-chemical damage model for stress-assisted corrosion. Electrochim Acta 323(10):134795 
9. Zhao J, Chen Z, Mehrmashhadi J, Bobaru F (2018) Construction of a peridynamic model for transient advectiondiffusion problems. Int J Heat Mass Transf. https://doi.org/ 10.1016/j.ijheatmasstransfer.2018.06.075

10. Wang H (2019) Peridynamics and nonlocal diffusion models: fast numerical methods. In: Voyiadjis $G$ (eds) Handbook of nonlocal continuum mechanics for materials and structures. https://doi.org/10.1007/978-3-319-58729-5_ 35

11. Talamadupula KK, Povolny S, Prakash N, Seidel GD (2021) Piezoresistive detection of simulated hotspots and the effects of low velocity impact at the mesoscale in nanocomposite bonded energetic materials via multiphysics peridynamics modeling. Comput Mater Sci 188:110211

12. Jafarzadeh S, Wang L, Larios A, Bobaru F (2021) A fast convolution-based method for peridynamic transient diffusion in arbitrary domains. Comput Meth Appl Mech Eng 375:113633

13. Diana V, Carvelli V (2020) An electromechanical micropolar peridynamic model. Comput Meth Appl Mech Eng 365:112998

14. Kulkarni SS, Tabarraei A (2020) An ordinary state based peridynamic correspondence model for metal creep. Eng Fract Mech 233:107042

15. Yang D, Dong W, Liu X, Yi SH, He X (2018) Investigation on mode-I crack propagation in concrete using bond-based peridynamics with a new damage model. Eng Fract Mech 199:567-581

16. Javili A, Morasata R, Oterkus E, Oterkus S (2019) Peridynamics review. Math Mech Solids 24(11):3714-3739

17. Sun W, Fish J (2019) Superposition-based coupling of peridynamics and finite element method. Comput Mech 64(1):231-248

18. Wang X, Shank SK, Alireza T (2019) Concurrent coupling of peridynamics and classical elasticity for elastodynamic problems. Comput Methods Appl Mech Eng 344:251-275

19. Sumelka W (2017) On fractional non-local bodies with variable length scale. Mech Res Commun 86:5-10

20. Song X, Khalili N (2019) A peridynamics model for strain localization analysis of geomaterials. Int $\mathrm{J}$ Numer Anal Methods Geomech 43:77-96

21. Foster JT, Silling SA, Chen WW (2010) Viscoplasticity using peridynamics. Int $J$ Numer Meth Eng 81(10): 1242-1258

22. Sun C, Huang Z (2016) Peridynamic simulation to impacting damage in composite laminate. Compos Struct 138:335-341

23. Kazemi SR (2020) Plastic deformation due to high-velocity impact using ordinary state-based peridynamic theory. Int J Impact Eng 137:103470

24. Wang H, Xu Y, Huang D (2019) A non-ordinary state-based peridynamic formulation for thermo-visco-plastic deformation and impact fracture. Int J Mech Sci 159(1):336-344

25. dell'Isola F, Andreaus U, Placidi L (2015) At the origins and in the vanguard of peridynamics, non-local and highergradient continuum mechanics: an underestimated and still topical contribution of Gabrio Piola. Math Mech Solids 20(8):887-928

26. Silling SA (2000) Reformulation of elasticity theory for discontinuities and long-range forces. J Mech Phys Solid 48(1):175-209
27. Javili A, McBride AT, Steinmann P (2019) Continuumkinematics-inspired peridynamics. J Mech Physics Solids 131:125-146

28. Zheng G, Shen G, Xia Y, Hu P (2020) A bond-based peridynamic model considering effects of particle rotation and shear influence coefficient. Int $\mathrm{J}$ Numer Methods Eng 121:93-109

29. Lee J, Liu W, Hong J-W (2016) Impact fracture analysis enhanced by contact of peridynamic and finite element formulations. Int J Impact Eng 87:108-119

30. Stręk AM (2010) Production and study of polyether auxetic foam. Mech Control 29(2):78-87

31. Nowak M, Nowak Z, Pęcherski RB, Potoczek M, Śliwa RE (2013) On the reconstruction method of ceramic foam structures and the methodology of young modulus determination. Arch Metal Mater 58(4):1219-1222

32. Pęcherski RB, Nowak M, Nowak Z (2017) Virtual metallic foams, applications for dynamic crushing analysis. Int $\mathbf{J}$ Multiscale Comput Engng 15:431-442

33. Postek E, Pęcherski RB, Nowak Z (2019) Peridynamic simulation of crushing processes in copper open-cell foam. Arch Metall Mater 64(4):1603-1610

34. Amani J, Oterkus E, Areias P, Zi G, Nguyen-Thoi T, Rabczuk T (2016) A non-ordinary state-based peridynamics formulation for thermoplastic fracture. Int J Impact Eng 87:83-94

35. Warren TL, Silling SA, Askari A, Weckner O, Epton MA, Xu J (2009) A non-ordinary state-based peridynamic method to model solid material deformation and fracture. Int J Solids Struct 46:1186-1195

36. Huber MT (2004) Właściwa praca odkształcenia jako miara wytężenia materiału (in Polish), Czasopismo Techniczne, Lwów (1904), Translated as "Specific Work of Strain as a Measure of Material Effort". Arch Mech 56:173-190

37. Silling SA (2003) Dynamic fracture modelling with a meshfree peridynamic code. In: Bathe KJ (ed) Computational fluid and solid mechanics. Elsevier, pp 641-644

38. Flanagan DP, Taylor LM (1987) An accurate algorithm for stress integration with finite rotations. Comput Methods Appl Mech Engrg 62(3):305-320

39. Camacho GT, Ortiz M (1997) Adaptive lagrangian modelling of ballistic penetration of metallic targets. Comput Methods Appl Mech Eng 142:269-301

40. Warren TL, Tabarra MR (2000) Simulation of the penetration of 6061-t6511 aluminium targets by spherical-nosed VAR 4340 steel projectiles. Int $J$ Solids Struct 37:4419-4435

41. Nowak M, Nowak Z, Pęcherski RB, Potoczek M, Śliwa RE (2018) Assessment of failure strength of real alumina foams with use of the periodic structure model. Arch Metal Mater 63(4):1901-1906

42. Peirce D, Shih CF, Needleman A (1984) A tangent modulus method for rate dependent solids. Comput Struct 18(5):875-887

43. Parks ML, Littlewood DJ, Mitchel JA, Silling SA (2012) Peridigm users' guide. Sandia report, Sandia National Laboratories

44. Open Source Peridigm program repository (2020). https:// github.com/peridigm/peridigm. Accessed 10 Oct 2020

45. Littlewood DJ, Volgler T (2020) Modeling dynamic fracture with peridynamics, finite element modeling and 
contact. In: 11th US National Congress on computational mechanics, July 25-28, 2011. https://www.osti.gov/ servlets/purl/1106568. Accessed 10 Oct 2020

46. Littlewood DJ (2020) Introduction to peridynamic modeling and applications. https://www.osti.gov/servlets/purl/ 1511976. Accessed 10 Oct 2020

47. The Trilinos Project Team (2020) The Trilinos project website. https://trilinos.github.io. Accessed 10 Oct 2020

48. MSC Software (2020) https://www.mscsoftware.com/ product/patran. Accessed 10 Oct 2020

49. Mills-Curran WC, Gilkey AP, Flanagan DP (1988) Exodus: a finite element file format for pre- and postprocessing. https://www.osti.gov/servlets/purl/6902151. Accessed 10 Oct 2020

50. The CUBIT Tool Suite Web Page (2020). http://cubit. sandia.gov. Accessed 10 Oct 2020

51. GiD The personal pre and post processor (2020). https:// www.gidhome.com/. Accessed 10 Oct 2020

52. Silling SA, Askari EA (2005) Meshfree method based on the peridynamic model of solid mechanics. Comput Struct 83:1526-1535

53. Behzadinasab M, Vogler TJ, Peterson AM, Rahman J, Foster JT (2018) Peridynamics modeling of a shock wave perturbation decay experiment in granular materials with intra-granular fracture. J Dyn Behav Mater 4:529-542
54. Germain P (2020) The method of virtual power in the mechanics of continuous media, I: second-gradient theory. Math Mech Complex Syst 8(2):153-190

55. Reiher JC, Giorgio I, Bertram A (2017) Finite element analysis of polyhedra under point and line forces in secondstrain gradient elasticity. J Eng Mech 143(2):04016112

56. Mitchell JA, Silling SA, Littlewood DJ (2016) A positionaware linear solid constitutive model for peridynamics, SAND2016-12377J. Accessed 10 Oct 2020

57. Mitchell JA (2013) On the "DSF" and the "Dreaded Surface Effect". https://cfwebprod.sandia.gov/cfdocs/ CompResearch/docs/SAND2013-1927C.pdf. Accessed 10 Oct 2020

58. ScanIP+FE (2014). https://www.synopsys.com/ simpleware.html. ver.7.0. Accessed 10 Oct 2020

59. Geuzaine C, Remacle J-F (2020) A three-dimensional finite element mesh generator with built-in pre- and post-processing facilities. https://gmsh.info/. Accessed 10 Oct 2020

60. Zohdi T, Wriggers P (2008) An introduction to computational micromechanics. Springer, Berlin

Publisher's Note Springer Nature remains neutral with regard to jurisdictional claims in published maps and institutional affiliations. 